$\xi=-1$

\title{
Solvent Extraction Method for Separation and Determination of Zn (\|) by Using of Imidazole Derivative
}

\author{
Shawket K. Jawad ${ }^{1 *}$, Nemah Sahib Mohummed Husien² \\ ${ }^{1}$ Department of Chemistry, College of Education for girls, Iraq. \\ ${ }^{2}$ Department of Chemistry, College of Education for girls, Iraq.
}

\begin{abstract}
Solvent extraction as sensitive and effective method for separation, pre concentration and determination $\mathrm{Zn}^{+2}$ after converted the cation into ion pair complex by combination, coordinately with complexion agent 2-[(2-methylphenyl)azo]-4,5-diphenyl imidazol (MPADPI). Spectrophotometric study shows wave length for maximum absorbance of complication reagent equal to $\lambda_{\max }=405 \mathrm{~nm}$ but maximum absorbance wave length for ion pair complex extracted of $\mathrm{Zn}^{+2}$ equal to $\lambda_{\max }=535 \mathrm{~nm}$. The experimental studies for pin point the optimum conditions of extraction shows $\mathrm{pH}=10$ in presence $50 \mu \mathrm{g} \mathrm{Zn^{+2 }}$ in $5 \mathrm{~mL}$ with shaking time equal 10 min., by using slope analysis method and mole ratio method demonstrated the structure of the ion pair association complex was $[1: 1]^{2+} ; 2 \mathrm{Cl}^{-},[\mathrm{MPADPI}-\mathrm{Zn}]^{2+} ; 2 \mathrm{Cl}^{-}$. The experimental study about organic solvent effect shows there was not any linear relation between dielectric constant of organic solvent and the values that means there was not any effect for polarity of organic solvent on extraction efficiency but there was un effect for organic solvent structure .Temperature effect study shows the extraction method was exothermic behavior with thermodynamic factor equal to $\Delta \mathrm{H}_{\mathrm{ex}}=-0.0255 \mathrm{kJmol}^{-1}, \Delta \mathrm{G}_{\mathrm{ex}}=-19.4005 \mathrm{kJmol}^{-1}, \Delta \mathrm{S}_{\mathrm{ex}}=69.78 \mathrm{~J} \mathrm{molK}-1$ and other studies involved synergism effect, methanol effect ,spectrophotometric determination of $\mathrm{Zn}^{+2}$ in different samples.
\end{abstract}

Keywords: Zinc(II), Solvent extraction, ion pair, separation, spectrophotometric determination.

\section{Introduction}

By using solvent extraction as sensitive and effective method for separation ion pair association complex of binding $\mathrm{Zn}^{2+}$ coordinately with complexation reagent MPADPI in order to determination Zinc(II) in different samples, due to total features for solvent extraction method may used in wide spread application for separation the more of elements as cations or anions with different applications, there was many application in (2014) extracted Nickel(II) as chloroanion complex by DB18C6 and coupled with cloud with cloud point extraction method and in presence $0.25 \mathrm{NaCl}$ and TritonX-100 and application this method for determination $\mathrm{Zn}$ (II) in different samples after pinpoint the optimum condition ${ }^{[1]}$. The researcher(2012) extracted $\mathrm{Pb}^{2+}$ and $\mathrm{Cd}^{2+}$ and determined them in different samples by using two complexing agents 2- [(benzothiazolyl)azo]-4- benzylphenol (BTABP) and 2-[(3-bromophenyl) azo] 4,5-diphenyl imidazole (BPADPI) coupled with CP5 method with Troton $\mathrm{x}-100^{[2]}$. Gharabaghi and others (2013) by application solvent extraction extracted $\mathrm{Ni}$ and $\mathrm{Zn}$ from acidic solution by $\mathrm{Di}(2-$ ethylhexyl) phosphoric acid (Cyanex272), and pinpointed the optimum condition and application this method to extracted and determined these ions from waste water ${ }^{[3]}$. There was many application for solvent extraction to separation and determination metal elements as cations or as anions and applicable their methods for determination these elements in different samples after determination optimum condition ${ }^{[4-10]}$.And in preferential research involved separation and extraction Lanthanum(III) by joined cloud point with salvation ${ }^{[11]}$.By application Onium method for separation and spectrophotometric determination of $\mathrm{Co}$ (II) joined with cloud point extraction methodology ${ }^{[12]}$. Extracted many metal ions by solvent extraction methods ${ }^{[13-19]}$.

\section{Experimental}

For spectrophotometric studies and absorbance measurements was used double beamUv-Vis spectrophotometer and single beam Uv -Vis spectrophotometer, preparing stock solution of Zinc(II) $1000 \mu \mathrm{g} / \mathrm{mL}$ by dissolved $0.286 \mathrm{~g}$ in $100 \mathrm{~mL}$ distilled water in presence $1 \mathrm{~mL}$ of $\mathrm{HCl}$, and for determination $\mathrm{Zn}^{2+}$ in aqueous phase following Dithizone method ${ }^{[20]}$.

\section{Method supported}

We are taking $5 \mathrm{~mL}$ aqueous solution contain $50 \mu \mathrm{g} \mathrm{Zn}{ }^{2+}$ at $\mathrm{pH}$ $=10$ and added to it $5 \mathrm{~mL}$ of $1 \times 10^{-4} \mathrm{M}$ (MPADPI) dissolved in chloroform and shaking for $10 \mathrm{~min}$ and then separate the aqueous phase from the organic phase and measure the absorbance of ion complex formed in organic phase at $\lambda \max =535 \mathrm{~nm}$ against blank preparing at the same manner without $\mathrm{Zn}^{2+}$ ion and the aqueous phase treated according to spectrophotometric dithizone method ${ }^{[20]}$ to determine the remainder quantity of $\mathrm{Zn}^{2+}$ ion in aqueous phase and by subtraction the quantity from the total quantity of $\mathrm{Zn}^{2+}$ ion aqueous solution to determine the transfer quantity into organic phase to formation ion pairs complex the calculate distribution ratio $\mathrm{D}$ :

$D=\frac{\left[Z n^{2+}\right]_{\text {org }}}{\left[\mathrm{Zn}^{2+}\right]_{\text {aq }}}$

By following Dithiazon method ${ }^{[20]}$ on $5 \mathrm{~mL}$ aqueous solutions contain rising quantity of $\mathrm{Zn}^{2+}$ ion the results calibration carve demonstrated in Figure(1) 


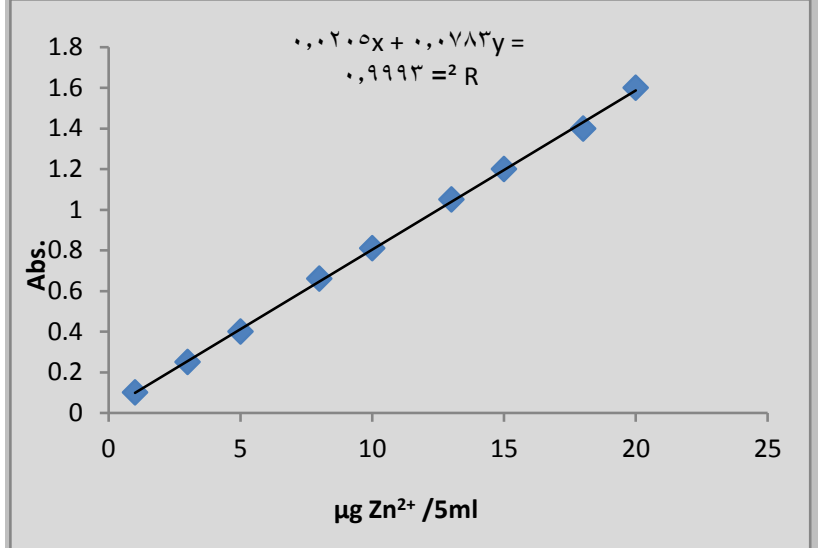

Figure 1: Calibration carve for determination $\mathrm{Zn}^{2+}$ in aqueous solutions

\section{Results and discussion}

After preparing organic reagent MPADPI according to previous study ${ }^{[21]}$ according to mechanism below:<smiles>Cc1ccccc1N</smiles>

2-Methylaniline<smiles>c1ccc(-c2nc[nH]c2-c2ccccc2)cc1</smiles><smiles>Cc1ccccc1N=[N+]</smiles>

Diazonium salt
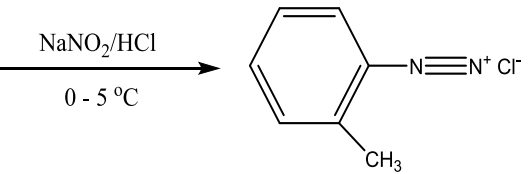

4,5-diphenyl imidazol
Diazonium salt

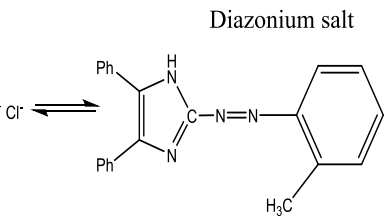

2-[(2-methylphenyl)azo]-4,5-diphenyl imidazol (MPADPI)
UV-Vis spectrum of this organic reagent dissolved in chloroform demonstrate the wave length of maximum absorbance for this reagent was $\lambda_{\max }=405 \mathrm{~nm}$ but the ion pair complex with $\mathrm{Zn}^{2+}$ shows in its UV-Vis spectrum the maximum absorbance appear at wave length was $\lambda_{\max }=535 \mathrm{~nm}$ as in Figure[2].

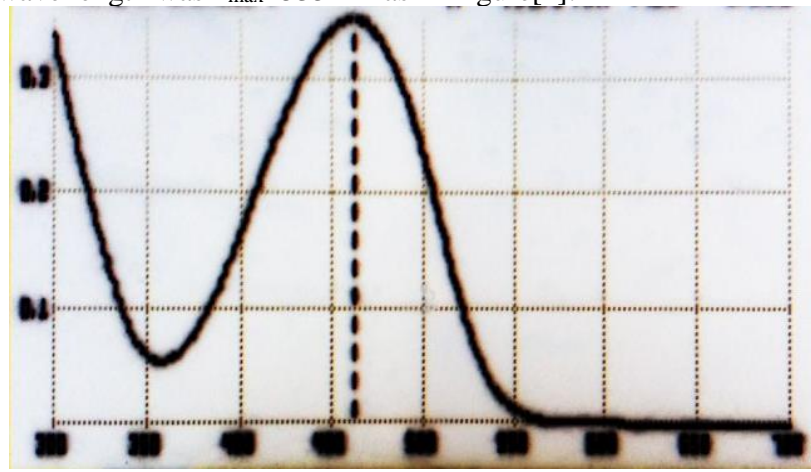

(a)

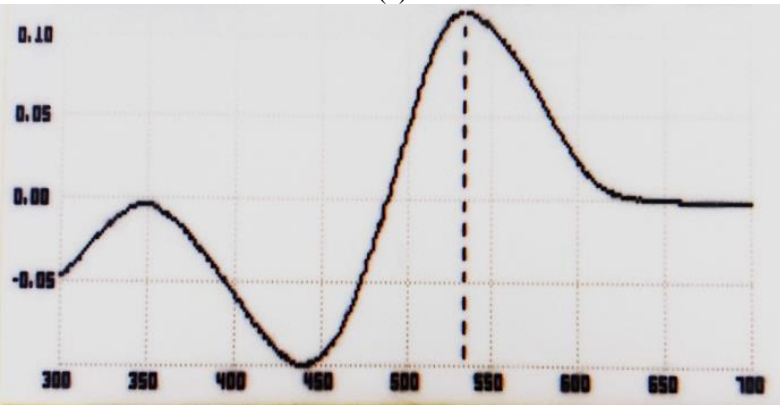

(b)

Figure 2: UV -Vis spectra

A- for organic reagent MPADPI.

$\mathrm{B}$ - for ion pair association complex between $\mathrm{Zn}^{2+}$ and organic reagent MPADPI.

\subsection{Effect of pH}

Aqueous solutions $5 \mathrm{~mL}$ in volume contain $50 \mu \mathrm{g} \mathrm{Zn}^{2+}$ and different $\mathrm{pH}$ at the range (4-11), then added to each solution $5 \mathrm{~mL}$ of organic reagent solution MPADPI dissolved in chloroform at $1 \times 10^{-4}$ and then shaking these solution for 10 minute afterward separation organic phase from aqueous phase ,then measure the absorbance of the organic phase at $\lambda_{\max }=535 \mathrm{~nm}$ against blank prepared at the same manner without $\mathrm{Zn}^{2+}$,but the aqueous phase treated according to dithizone method and return to calibration curve to determined Distribution ratio $\mathrm{D}$ at each $\mathrm{pH}$ value the results were as in Figures 3,4:

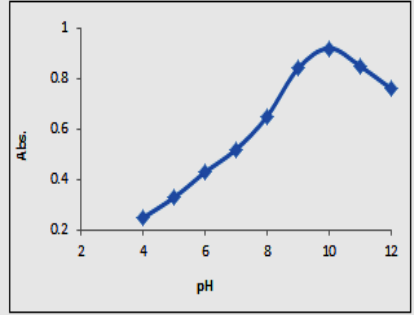

Figure (3): Effect of $\mathrm{pH}$ on the formation and stability of ion pair complex

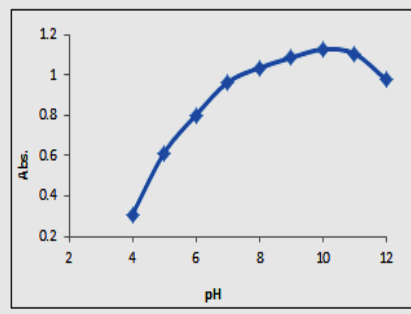
efficiency
Figure(4) : Effect of $\mathrm{pH}$ on the Extraction

The result demonstrate $\mathrm{pH}=10$ was the optimum value which is giving higher extraction efficiency because at this $\mathrm{pH}$ giving best binding between organic reagent MPADPI with $\mathrm{Zn}^{2+}$ ion and more stable, any $\mathrm{pH}$ less than optimum value it is not suitable for formation complex, so $\mathrm{pH}$ value more than optimum give decline in extraction efficiency and complex formation by effect increasing $\mathrm{OH}^{-}$ion in aqueous solution which is prevent the complex formation.

\subsection{Effect of metal ion concentration}

Preparing a series of aqueous solutions $5 \mathrm{~mL}$ in volume contain rising quantity of $\mathrm{Zn}^{2+}$ ion at $\mathrm{pH}=10$ and added to each one $5 \mathrm{~mL}$ of BPADPI dissolved in chloroform at $1 \times 10^{-4} \mathrm{M}$ and shaking for $10 \mathrm{~min}$, then separated aqueous phase from organic and complete the experimental as the general method the results were as in Figures 5,6:

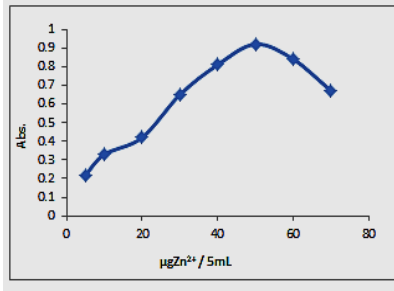

Figure(5): Effect of metal ion concentration on the formation of ion pair complex.

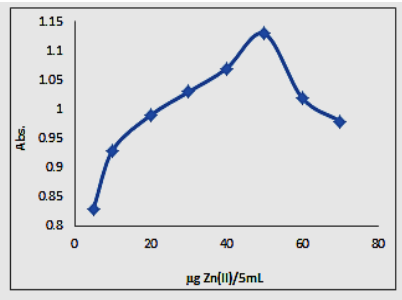

Figure (6) Effect of metal ion concentration on extraction efficiency and $\mathrm{D}$ values
The experimental study show $50 \mu \mathrm{g}$ was the optimum concentration of $\mathrm{Zn}^{2+}$ ion in $5 \mathrm{~mL}$ aqueous solution to give higher absorbance and $\mathrm{D}$ value that is mean at this concentration reach to maximum efficiency for formation of ion pair complex and extraction, whereas the concentration of metal ion is eon of the thermodynamic factor then optimum value help to give better the thermodynamic equilibrium and any concentration less than optimum not suitable to reach the best equilibrium ,so concentration more than optimum giving decrease in extraction efficiency according to mass active law .

\subsection{Variation shaking time}

$5 \mathrm{~mL}$ aqueous solutions contain $50 \mu \mathrm{g} \mathrm{Zn}^{2+}$ at $\mathrm{pH}=10$ added to each one $5 \mathrm{~mL}$ of $1 \times 10^{-4}$ BPADPI dissolved in chloroform and shaking these solutions for different shaking time afterward separate the aqueous phase from the organic and complete the work as in the general method. The results were as in Figures 7,8: 


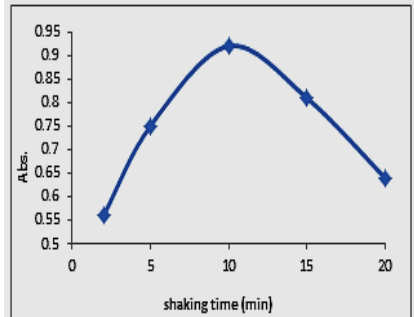

Figure (7): Effect of shaking from ion complex formation

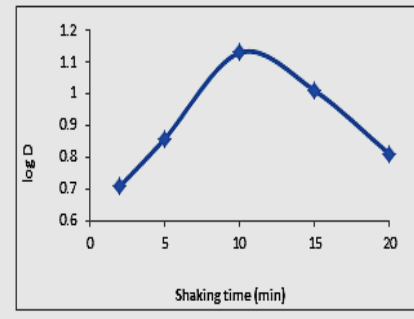

Figure(8) : effect of variation shaking time on extraction efficiency
Shaking time represent kinetic law effect on indirect extraction method. The results value for shaking time giving higher extraction efficiency and help to reach best equilibrium for formation ion pair association complex, any shaking time less than optimum not suitable for extraction so that shaking time more than optimum value.

\subsection{Stoichiometry}

By using mole ratio and slope analysis method for determination more probable structure of ion pair complex extracted the results demonstrated in Figures 9,10:

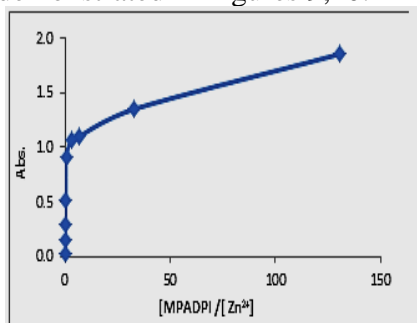

Figure(9): mole ratio method

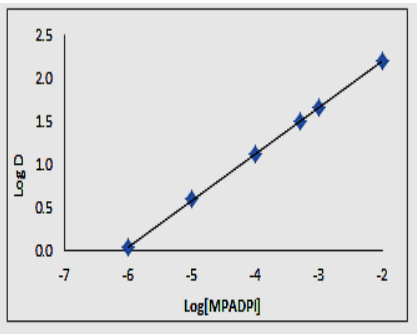

Figure(10):Slope analysis method
The results appear structure of ion pair complex extracted was $[1: 1]^{2+}$ anion

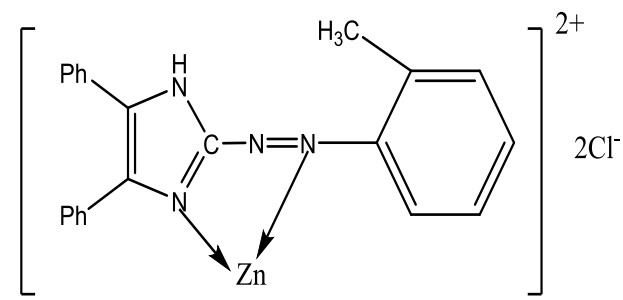

\subsection{Organic solvent effect}

A series of aqueous solution $5 \mathrm{~mL}$ in volume contain $50 \mu \mathrm{g} \mathrm{Zn}^{2+}$ at $\mathrm{pH}=10$ added to each one $5 \mathrm{~mL}$ of $1 \times 10^{-4} \mathrm{M}$ solution of BPADPI dissolved in different organic solvents and shaking them for 10minutes the results were as in Table (1):

Table 1: Effect of Different Organic Solvents

\begin{tabular}{|c|c|c|c|}
\hline Organic solvents & $\begin{array}{c}\text { Dielectric } \\
\text { constant }\end{array}$ & $\begin{array}{c}\text { Abs. at } \\
\lambda_{\max }=535 \mathrm{~nm}\end{array}$ & $\mathrm{D}$ \\
\hline Nitrobenzene & 35.49 & 1.14 & 16.52 \\
\hline 1,2-Dichloroethane & 10.650 & 1.55 & 22.63 \\
\hline DiChloromethane & 9.080 & 1.23 & 17.53 \\
\hline Chlororbenzene & 5.708 & 0.83 & 10.44 \\
\hline Chloroform & 4.806 & 0.92 & 13.44 \\
\hline Benzene & 2.804 & 0.42 & 4.85 \\
\hline Toluene & 2.438 & 0.16 & 2.84 \\
\hline
\end{tabular}

The results shows there was not any linear relation between dielectric constant of the solvents and distribution ratio for extraction that is mean there was not any effect of polarity of organic solvent on extraction efficiency as well as the results appears there is un effect for organic solvent structure on extraction efficiency and this demonstrate the participation of organic solvent in the formation of ion pair complex extracted and its stability.

\subsection{Thermodynamic study}

Aqueous solution $5 \mathrm{~mL}$ in volume contain $50 \mu \mathrm{g} \mathrm{Zn}^{2+}$ at $\mathrm{pH}=10$ added to each solution $5 \mathrm{~mL}$ of $1 \times 10^{-4}$ MBPADPI dissolved in chloroform and shaking these solution for $10 \mathrm{~min}$ the results were as in Figures 11,12:

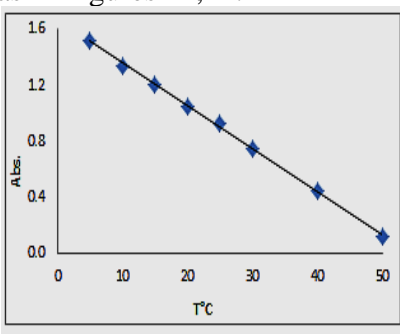

Figure(1l):Effect of temperature on the formation of ion pair complex

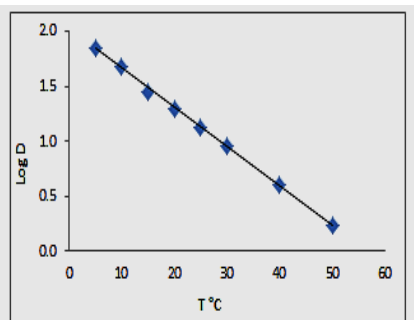

Figure(12):Effect of temperature on the extraction efficiency and $D$ values
Calculate extraction constant Kex according to relation below

$$
K_{e x}=\frac{D}{\left[Z n^{2+}\right][B P A D P I]}
$$

And draw $\log$ Kex against $1 / \mathrm{TK}$ the results as in Figure (13):

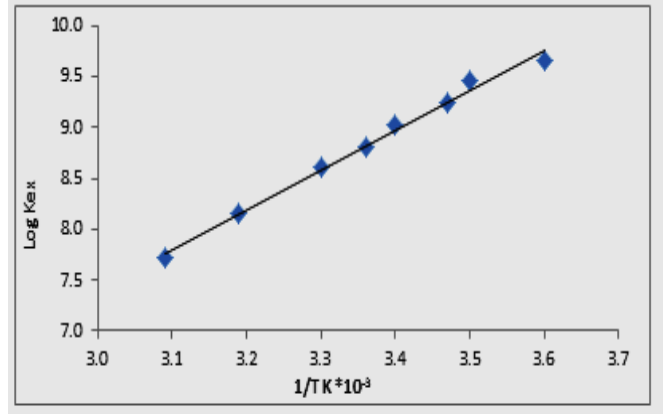

Figure (13): Extraction constant $\mathrm{Kex}$ as a function to $\mathrm{T} \mathrm{K}$

From the slope of the relation above and relation below calculated thermodynamic data of extrication:

$$
\begin{gathered}
\text { Slope }=\frac{-\Delta H_{e x}}{2.303} \\
\Delta \mathrm{G}_{\mathrm{ex}}=-\mathrm{RT} \ln \mathrm{K}_{\mathrm{ex}} \\
\Delta \mathrm{G}_{\mathrm{ex}}=\Delta \mathrm{H}_{\mathrm{ex}}-\mathrm{T} \Delta \mathrm{S}_{\mathrm{ex}}
\end{gathered}
$$

$\Delta \mathrm{H}_{\mathrm{ex}} \quad \mathrm{KJ} / \mathrm{mol} \Delta \mathrm{G}_{\mathrm{ex}} \quad \mathrm{KJ} / \mathrm{mol} \Delta \mathrm{S}_{\mathrm{ex}} \quad \mathrm{Jmol}^{-1} \mathrm{~K}^{-1}$ $-0.0275-19.400569 .7800$

The results appear extraction method was exothermic relation, so the high value of entropy $\Delta S_{\text {ex }}$ demonstrates the method of extraction is entropic in region.

\subsection{Synergism effect}

Series of aqueous solutions at $5 \mathrm{~mL}$ in volume contain $100 \mu \mathrm{g}$ $\mathrm{Zn}^{2+}$ at $\mathrm{pH}=10$ added to each solution $5 \mathrm{~mL}$ of organic solution of BPADPI dissolved in chloroform at $1 \times 10^{-4} \mathrm{M}$ in presence different concentrations MIBK or TBP in organic phase and shaking these solutions for $15 \mathrm{~min}$. and then separated the aqueous phase from the organic phase and complex the experiment as in the general method the results were as in Figures 14,15:

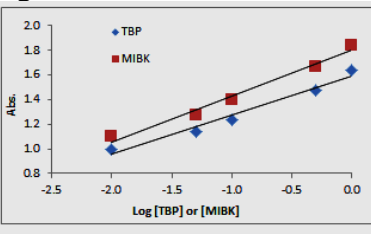

Figure(14): Increasing ion pair complex formation by increasing concentration of MIBK or TBP

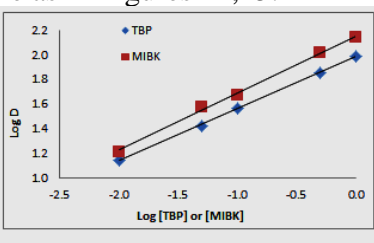

Figure(15): Increasing extraction efficiency and $D$ values with increasing concentration of
In presence MIBK and TRP in organic phase whereas these compounds replace the water molecules bonding in the empty 
coordination position of $\mathrm{Zn}^{2+}$ in the complex and increasing the hydrophobicity of the ion pair complex and increase the partitioning to the organic phase.

\subsection{Effect of methanol}

Aqueous solution $5 \mathrm{~mL}$ in volume contain $100 \mu \mathrm{g}$ of $\mathrm{Zn}^{2+}$ ion at $\mathrm{pH}$ $=10$ and in the presence rising percentage of method added to each solution $5 \mathrm{~mL}$ of BPADPI dissolved in chloroform at $1 \times 10^{-4} \mathrm{M}$ and shake these solutions for $15 \mathrm{~min}$. then separated the organic phase from the aqueous phase and complex the work as in the general method. The results were as in Figures 16,17:

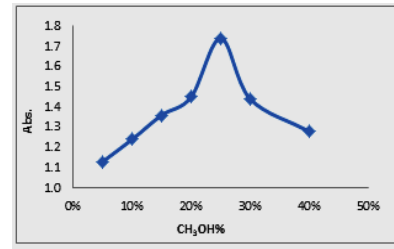

Figure (16): Effect of increasing methanol percentage on ion pair complex formation

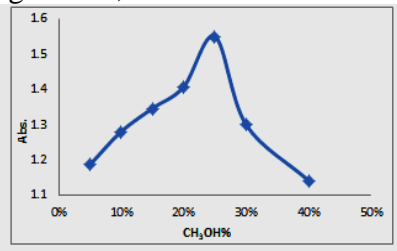

Figure (17): Effect of increasing methanol percentage on extraction efficiency
The results demonstrate presence methanol in the aqueous solution with $\mathrm{Zn}^{2+}$ ion effect to increase the extraction efficiency and the optimum percentage of methanol was $25 \%$, because the presence methanol decreases the dielectric constant and polarity of aqueous phase and destroy the hydration shell of the metal ion and partition the ion pair complex to the organic phase.

\subsection{Spectrophotometric determination}

By application this method of extraction at optimum conditions and in order to determination $\mathrm{Zn}^{2+}$ in different samples preparing calibration carve as in the Figure (18)

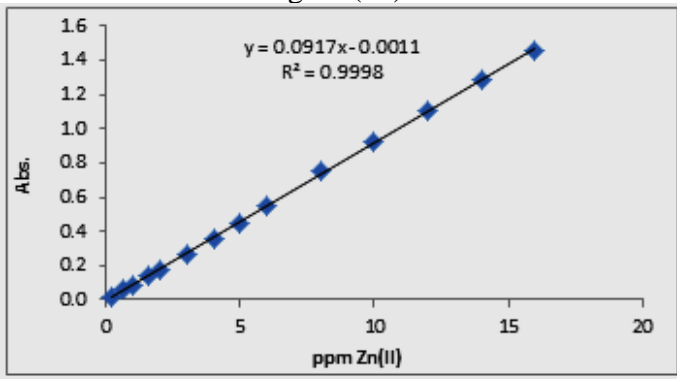

Figure (18): Spectrophotometric determination of $\mathrm{Zn}$ (II) by organic reagent MPADPI

\begin{tabular}{|c|c|}
\hline Parameters & Values \\
\hline$\lambda_{\max }$ & $535 \mathrm{~nm}$ \\
\hline RSD & 0.882 \\
\hline Sandell's Sensitivity & $1.091 \times 10^{-7} \mu \mathrm{g} . \mathrm{cm}^{-2}$ \\
\hline Molar absorbtivity & $5.994 \times 10^{3}$ \\
\hline Detection limit & $2.40 \times 10^{-4} \mathrm{M}$ \\
\hline
\end{tabular}

And after determination $\mathrm{Zn}^{2+}$ in different samples the results were as in Table (2):

Table 2: Applications

\begin{tabular}{|l|l|}
\hline Samples & $\mathrm{ppm} \mathrm{Zn}(\mathrm{II})$ \\
\hline Agriculture soil (Kufa city) & 1.5 \\
\hline Agriculture soil(mishkhab city) & 2.5 \\
\hline Euphrates river (Kufa city) & 0.122 \\
\hline Euphrates river(mishkhab city) & 0.143 \\
\hline Vegetables & 0.225 \\
\hline Sheep meat & 0.254 \\
\hline Beef & 0.316 \\
\hline Chickens & 0.165 \\
\hline
\end{tabular}

\section{References}

[1] Shawket KJ \& Ebaa AA, "Cloud point extraction for separation, Pre concentration and extraction of Nickel (II) as chloroamoniaby use crown ether DB18C6 coupled with spectrophotometric determination", International Journal for science and Technology, Vol.9, No.1, (2014).

[2] Shawket KJ \& Jihan RM, "Cloud point extraction methodology for Separation and micro amounts Determination of lead (II) and Cadmium(II) Ion", Iraqi National Journal of Chemistry, Vol.47, (2012), pp.401-412.

[3] Gharabaghi M, Irannajad M \& Azadmehr AR, "Separation of nickel and zinc ions in a synthetic acidic solution by solvent extraction using D2EHPA and Cyanex 272", Physicochemical Problems of Mineral Processing, Vol.49, No.1, (2013), pp.233242.

[4] Jawad SK \& FA W, "AL-Ghurabi, Liquid-Liquid extraction method for extraction $\mathrm{Zn}$ (II) and Cd (II) from aqueous solutions by two synthesized azo organic reagent", Al-Qadysia Journal, Vol.1, No.2, (2013), pp.23-50.

[5] Tian M, Jin Q, Quan X \& Liao W, Journal of chemical and engineering data, Vol.56, No.5, (2011), pp.2225-2229.

[6] Jawad SK, Ali SK \& Hameed, SM, "Spectrophotometric Determination of Micro Amount of Copper (II) in Different Enviromental and Vital Samples by New Organic Reagent", Iraqi National Journal of Chemistry, Vol.43, (2011), pp.299-309.

[7] Yin S, Wu W, Bian X, Luo Y \& Zhang F, "Solvent extraction of lanthanum ion from chloride medium by di-(2-ethylhexyl) phosphoric acid with a complexing method", International Journal of Nonferrous Metallurgy, Vol.2, No.2, (2013), pp.75-79.

[8] John CU \& Augustus UB, "Extraction of $\mathrm{Cu} 2+, \mathrm{Co} 2+$ and $\mathrm{Ni2}+$ ions from aqueous solutions of bromide ion using 1-phenyl-3methyl-4-trichloro acetyl pyrazolone-5 in benzene and hexane", Carbon (C), Vol.6, No.9, pp.95-101.

[9] Shawket KJ \& Faris HH, Journal of chemistry and Materials Research, Vol.7, No.3, (2015), pp.63-72.

[10] Shawket KJ \& Moosa OK \& Alaa SA, Rasayan J chem., Vol.11, No.1, (2018), pp.245-253.

[11] Shawket KJ \& Faris HH, Journal of global pharma Technology, Vol.11, No.9, (2018), pp.83-91.

[12] Barache UB, Shaikh AB, Kamble GS, Lokhande TN, Gurame VM \& Gaikwad SH, "A Novel Simple, Rapid, Cost Effective and Selective Extractive Spectrophotometric Method for the Determination of Bismuth (Iii) From Environmental", Pharmaceutical Samples And Synthetic Mixtures, Vol.6, No.8, (2017), pp.1915-1938.

[13] Shaikh AB, Barache UB, Lokhande TN, Kamble GS, Anuse MA \& Gaikwad SH, Rasayan Journal Chemistry, Vol.10, No.3, (2017).

[14] Barache UB, BShaikh A, Lokhande TN, Kamble GS, Anuse MA \& Gaikwad SH, Spectrochimica Acta part A: Molecular and Bimolecular Spectroscopy, Vol.189, (2018).

[15] Shawket KJ \& Mustafa NS, Natural Science Research, Vol.5, No.3, (2015).

[16] Yanjun L, Jie X, Yony X, Jingfeng W, Yaoguang C, \& Changhu X, International Journal of environmental Analytical Chemistry, Vol.95, No.3, (2015), pp.258-270.

[17] Mohammedi SZ \& Mohammed NM, Journal of Ao Ac International, Vol.98, No.1, (2015), pp.201-205.

[18] Jalbani N \& Soylak M, "Preconcentration/separation of lead at trace level from water samples by mixed micelle cloud point extraction", Journal of Industrial and Engineering Chemistry, Vol.29, (2015), pp.48-51.

[19] López-García I, Vicente-Martínez Y \& Hernández-Córdoba M, "Determination of very low amounts of free copper and nickel ions in beverages and water samples using cloud point extraction assisted by silver nanoparticles", Analytical Methods, Vol.7, No.9 (2015), 3786-3792.

[20] Marczenko Z \& Balcerzak M, Separation, pre concentration and spectrophotometry in inorganic analysis, Elsevier, (2000).

[21] Faten KA, MSc Thesis, Kufa University, Faculty of education for girls, (2009). 